\title{
Diabetes mellitus impairs circulating proangiogenic granulocytes
}

\author{
Roberta Cappellari $^{1,2} \cdot$ Marianna D'Anna ${ }^{1,2} \cdot$ Lisa Menegazzo $^{1,2} \cdot$ Benedetta Maria Bonora ${ }^{1,2} \cdot$ Mattia Albiero $^{1,2}$. \\ Angelo Avogaro ${ }^{2} \cdot$ Gian Paolo Fadini ${ }^{1,2}$ (10
}

Received: 28 November 2019 / Accepted: 28 February 2020 / Published online: 18 April 2020

(C) Springer-Verlag GmbH Germany, part of Springer Nature 2020

\begin{abstract}
Aims/hypothesis Cardiovascular risk in diabetes is at least in part attributable to defective angiogenesis. Since diabetes negatively affects blood cells involved in angiogenesis, we herein evaluated whether diabetes impairs proangiogenic granulocytes (PAGs).

Methods We characterised and quantified PAGs as CD49d $\mathrm{d}^{+}$granulocytes in peripheral blood of participants with type 2 or type 1 diabetes and in non-diabetic control participants. We evaluated PAG antigenic profile and assessed in vitro functional properties of CD49 $\mathrm{d}^{+}$granulocytes using 2D and 3D angiogenesis assays. We also quantified PAGs before and after glucose control with a sodium-glucose cotransporter 2 (SGLT2) inhibitor, dapagliflozin. In parallel, we measured $\mathrm{Ly}_{6 \mathrm{G}}{ }^{+} \mathrm{CD} 49 \mathrm{~d}^{+}$PAGs in streptozotocin-induced type 1-like diabetic mice vs non-diabetic control mice.

Results PAGs were composed of eosinophils $(>80 \%)$ and neutrophils $(<20 \%)$. Within both populations, CD49d identified $\mathrm{CXCR} 4^{\text {high }} /$ VEGFR $1^{\text {high }}$ cells. CD $49 \mathrm{~d}^{+}$granulocytes supported in vitro angiogenesis by endothelial cells significantly more than $\mathrm{CD}_{49 \mathrm{~d}^{-}}$control granulocytes, and physically interacted with endothelial cells. Granulocytes from type 2 diabetic participants had a profoundly impaired capacity to stimulate endothelial cell tubule formation compared with those from non-diabetic control participants. CD $49 \mathrm{~d}^{+}$PAGs were reduced by $30-40 \%$ and were functionally impaired in diabetic vs control individuals. PAG levels inversely correlated with plasma glucose $(r=-0.25 ; p=0.025)$ and significantly increased 1.8 -times after glucose control with dapagliflozin, which reduced $\mathrm{HbA}_{1 \mathrm{c}}$ by $1.0 \%(11 \mathrm{mmol} / \mathrm{mol})$. Levels of $\mathrm{Ly} 6 \mathrm{G}^{+} \mathrm{CD} 49 \mathrm{~d}^{+}$PAGs were also significantly reduced also in type 1 diabetic mice vs control mice.

Conclusions/interpretation We illustrate a significant impairment of PAGs in diabetes and provide evidence for a direct role of hyperglycaemia. These findings add mechanistic information to explain the defective angiogenesis in diabetes.
\end{abstract}

$\begin{array}{ll}\text { Abbreviations } \\ \text { ACR } & \text { Albumin/creatinine ratio } \\ \text { BM } & \text { Bone marrow } \\ \text { CCR3 } & \text { C-C motif chemokine receptor 3 } \\ \text { CXCR4 } & \text { C-X-C chemokine receptor type } 4 \\ \text { EPC } & \text { Endothelial progenitor cell } \\ \text { FSC-A } & \text { Forward scatter area }\end{array}$

Roberta Cappellari and Marianna D'Anna contributed equally to this work.

Electronic supplementary material The online version of this article (https://doi.org/10.1007/s00125-020-05142-3) contains peer-reviewed but unedited supplementary material, which is available to authorised users.

Gian Paolo Fadini gianpaolo.fadini@unipd.it

1 Veneto Institute of Molecular Medicine, Padova, Italy

2 Department of Medicine, University of Padova, Via Giustiniani 2, 35128 Padova, Italy

$\begin{array}{ll}\text { Ly6G } & \text { Lymphocyte antigen 6 complex locus G6D } \\ \text { MFI } & \text { Mean fluorescence intensity } \\ \text { MPO } & \text { Myeloperoxidase } \\ \text { PAG } & \text { Proangiogenic granulocyte } \\ \text { SGLT2 } & \text { Sodium-glucose cotransporter } 2 \\ \text { SSC-A } & \text { Side scatter area } \\ \text { SIGLEC } & \text { Sialic acid-binding immunoglobulin-type lectin } \\ \text { STZ } & \text { Streptozotocin } \\ \text { VEGF } & \text { Vascular endothelial growth factor } \\ \text { VEGFR } & \text { VEGF receptor }\end{array}$

\section{Introduction}

People with diabetes have a reduced life expectancy, with most excess mortality due to cardiovascular causes [1]. The mechanisms driving excess cardiovascular risk in diabetes are manifold and still incompletely understood. In addition to accelerating the onset of vascular occlusive diseases, diabetes worsens the outcome after acute myocardial infarction and 


\section{Research in context}

\section{What is already known about this subject?}

- Impaired angiogenesis contributes to cardiovascular risk in diabetes

- Diabetes depletes some types of blood-derived proangiogenic cells

- Proangiogenic CD49 $\mathrm{d}^{+}$neutrophils have been previously identified in mice

\section{What is the key question?}

- Is there any alteration in proangiogenic granulocytes in diabetes?

What are the new findings?

- We identified CD49 $\mathrm{d}^{+} \mathrm{CXCR} 4^{\text {high }}$ VEGFR $1^{\text {high }}$ human granulocytes and characterised their antigenic and proangiogenic properties

- Granulocytes from participants with diabetes showed impaired angiogenic support and the proportion of CD49 $\mathrm{d}^{+}$ proangiogenic granulocytes was reduced in type 1 and type 2 diabetes.

- Reduction in proangiogenic granulocytes was related to hyperglycaemia

How might this impact on clinical practice in the foreseeable future?

- These data provide additional mechanistic insight into the impairment in angiogenesis associated with diabetes

stroke [2-4]. It has been hypothesised that responses to ischaemia are compromised in patients with diabetes, at least in part because of defective angiogenesis $[5,6]$. The well-established blockade of angiogenesis in diabetes has multiple mechanisms [7], including alterations of hypoxia-related pathways, chronic inflammation, and reduction of bone marrow (BM)-derived proangiogenic cells. Among these, we have extensively characterised the defect of endothelial progenitor cells (EPCs) in individuals with diabetes and how reduction of BM-derived stem/progenitor cells predicted adverse cardiovascular outcomes $[8,9]$. Besides EPCs, other blood cell types can be involved in the proangiogenic response to tissue ischaemia, including monocyte-macrophages. Interestingly, diabetes is associated with reductions in the levels of socalled M2 (anti-inflammatory) macrophages [10], which exhibit a distinctive proangiogenic capacity [11]. Among inflammatory cells, neutrophils have also been shown to modulate angiogenesis, especially in the setting of cancer [12], for instance through secretion of vascular endothelial growth factor (VEGF) [13]. Recently, a specific population of CD $49 \mathrm{~d}^{+}$proangiogenic granulocytes (PAGs) in the murine neutrophil population has been characterised, with a similar population being observed in the human blood [14]. Given that diabetes impinges upon neutrophil levels and function, we hypothesised that this population of cells could be affected.

In the present study, we first characterised PAGs in the human blood and then explored whether diabetes is associated with changes in the levels and function of PAGs. Finally, we evaluated the role of hyperglycaemia in modulating PAGs.

\section{Methods}

Participants Diabetic and non-diabetic control participants were recruited at the University Hospital of Padova. The study was approved by the local ethics committee and all participants provided written informed consent. For the crosssectional study, we included participants with diabetes (type 2 or type 1) for at least 1 year and non-diabetic control participants, who were male or female, aged 18-80 years. Exclusion criteria were: acute disease or infection, haematological disorders, immunological disorders (such as rheumatoid arthritis, but excluding type 1 diabetes and autoimmune thyroid disease), immunosuppression or organ transplantation, pregnancy or lactation, and inability to provide informed consent. For all participants, we collected the following information: age, sex, disease duration (for individuals with diabetes), height and weight for the calculation of BMI, current smoking habit, prevalence of hypertension, and values for fasting plasma glucose, $\mathrm{HbA}_{1 \mathrm{c}}$, plasma total cholesterol, HDL-cholesterol, triacylglycerol (LDL-cholesterol was calculated using the Friedewald formula [15]), serum creatinine, and urinary albumin excretion rate (as urinary albumin/creatinine ratio [ACR] in $\mathrm{mg} / \mathrm{mmol}$ ). We also collected information on current glucose-lowering medications and other concomitant medications. Diabetic complications were defined as follows. Retinopathy was defined based on digital funduscopic examination and scored according to ETDRS (early treatment of diabetic retinopathy study) [16]. Neuropathy was defined as a history of symptoms suggestive of peripheral polyneuropathy 
confirmed by nerve conduction velocity or in the presence of pathologic autonomic neuropathy tests. Nephropathy was defined as an ACR $>30 \mathrm{mg} / \mathrm{g}(3.39 \mathrm{mg} / \mathrm{mmol})$ or eGFR (using Chronic Kidney Disease-Epidemiology Collaboration [CKD-EPI] equation [17]) $<60 \mathrm{ml} \mathrm{m^{-1 }}(1.73 \mathrm{~m})^{-2}$. Coronary artery disease was defined as a past history of myocardial infarction, coronary revascularisation or angiographic evidence of haemodynamically significant coronary stenosis. Peripheral arterial disease was defined as a history of claudication or rest pain, confirmed by angiographic or ultrasonographic evidence of haemodynamically significant stenosis of leg arteries, or as a history of peripheral revascularisation. Cerebrovascular disease was defined as a history of stroke or transient ischaemic attack or as evidence of asymptomatic carotid atherosclerosis. The metabolic syndrome and its components were defined based on the revised ATP-III definition [18].

To examine the effects of glucose control with sodiumglucose cotransporter 2 (SGLT2) inhibition, we measured PAGs in a subgroup of type 2 diabetic patients enrolled in a trial of dapagliflozin therapy (NCT02327039, for details see [9]).

Animals All animal protocols were approved by the local and national ethics committee and were conducted in compliance with the Guide for the care and use of laboratory animals, Eighth edition (2011). C57Bl/6J mice from an in-house colony (at the Veneto Institute of Molecular Medicine) were rendered diabetic by a single intraperitoneal injection of streptozotocin (STZ) at $175 \mathrm{mg} / \mathrm{kg}$ in $100 \mathrm{mmol} / \mathrm{l}$ sodium citrate buffer, $\mathrm{pH}$ 4.5. Blood glucose was measured using a point-of-care glucometer (FreeStyle Optium, Abbott, Rome, Italy). Only animals with persistently elevated glucose levels $(>16.7 \mathrm{mmol} / \mathrm{l})$ were considered diabetic and retained in the study. Experiments were performed 4 weeks after confirming hyperglycaemia. $\mathrm{C} 57 \mathrm{B1} / 6 \mathrm{~J}$ mice treated with vehicle and observed for 4 weeks were used as controls. Mice were randomly assigned to STZ or vehicle using the coin toss method and personnel in charge of assessing endpoints were blind to the treatment received by each mouse. Body weight was monitored weekly. In all animals we measured blood glucose, $\mathrm{HbA}_{1 \mathrm{c}}$, total cholesterol, triacylglycerol and creatinine using a point-of-care system (Allegro, Nova Biomedicals, Milan, Italy).

Flow cytometry Identification and quantification of PAGs was performed using fresh peripheral blood. Antibodies are listed in electronic supplementary material (ESM) Table 1. Cells were labelled with CD45, CD16, CD49d, C-X-C chemokine receptor type 4 (CXCR4) and VEGF receptor (VEGFR)1. After erythrocyte lysis, cells were analysed on a FACSCanto II instrument and scored using FACS Diva (both from Becton Dickinson [BD], Milan, Italy). We gated granulocytes in the morphologic side scatter area (SSC-A) vs forward scatter area (FSC-A) gate based on size and complexity. Then, we identified and scored the population of CD49 $\mathrm{d}^{+}$cells in the morphologic granulocyte gate. Contamination of the granulocytic CD $49 \mathrm{~d}^{+}$population was ruled out by staining with CD9, CD3, CD56, CD10, CD19, CD14, CD24, CD15, CD66b and CD11b; we examined expression of such markers on CD49 $\mathrm{d}^{+}$ cells in the granulocytic vs the mononuclear (lymphomonocytic) cell gate. From the morphologic granulocyte population, we identified neutrophils and eosinophils in the CD45 vs CD16 plot. In separate experiments, granulocyte identity in the CD45/CD16 plot was confirmed using intracellular staining with the neutrophil-specific marker myeloperoxidase (MPO), and the eosinophil-specific markers C-C motif chemokine receptor 3 (CCR3) and sialic acidbinding immunoglobulin-type lectin (SIGLEC)8. Per cent expression of CD49d was then evaluated separately in the neutrophil and eosinophil populations. We compared mean fluorescence intensity (MFI) of CXCR4 and VEGFR1 on gated CD49 $\mathrm{d}^{+}$and CD49d $\mathrm{d}^{-}$granulocytes, and then separated for neutrophils and eosinophils.

For quantification of murine PAGs, mice were killed and blood was collected by cardiac puncture. PAGs were identified and scored using a strategy similar to that developed in humans. Cells in the morphologically defined granulocyte population were stained for lymphocyte antigen 6 complex locus G6D (Ly6G) (eBioscience, Thermo Fisher Scientific, Monza, Italy) and CD49d (cat no. 564394, BD) in order to identify CD49d ${ }^{+}$ neutrophils $\left(\mathrm{Ly}_{6} \mathrm{G}^{+}\right)$and $\mathrm{CD} 49 \mathrm{~d}^{+}$eosinophils $\left(\mathrm{Ly} 6 \mathrm{G}^{-}\right)$. Eosinophil vs neutrophil identity of gated $\mathrm{Ly}_{6} \mathrm{G}^{+/-}$granulocytes was confirmed by SIGLEC-F staining. CD115 was used to rule out contamination with $\mathrm{CD} 49 \mathrm{~d}^{+}$mononuclear cells. Then, by costaining cells for CXCR4 and VEGFR1, we examined MFI on CD49 $\mathrm{d}^{+}$neutrophils or eosinophils, relative to the respective $\mathrm{CD} 4 \mathrm{~d}^{-}$control. Absolute cell counts were obtained multiplying relative cell counts by the number of white blood cells/ $\mu$ l of blood, obtained on a Sysmex XE-series haematology analyser (Sysmex Sverige, Kungsbacka, Sweden), which also yielded the automated differential cell counts. The same trained operator performed the analysis throughout the study.

Cell isolation Granulocytes were isolated from anticoagulated whole blood of healthy blood donors. Non-target cells were removed by immunomagnetic depletion (MACSxpress Human Neutrophil Isolation Kit, Miltenyi Biotec, Bologna, Italy) and erythrocytes were sedimented, yielding a granulocyte population with the same representation of neutrophils and eosinophils observed in whole blood.

In other experiments, $C D 49 \mathrm{~d}^{+}$granulocytes were separated from fresh peripheral blood using FACSAria (BD). We either sorted CD49 $\mathrm{d}^{+}$cells from the entire morphologically defined (SSC-A and FSC-A) granulocyte population or within the $\mathrm{CD} 6^{+}$(neutrophil) or $\mathrm{CD}^{-} 6^{-}$(eosinophil) subset of granulocytes. Elevated autofluorescence was also used to differentiate eosinophils from neutrophils [19]. To have 
definite confirmation that $\mathrm{CD} 16^{+} \mathrm{CD} 49 \mathrm{~d}^{+}$granulocytes were neutrophils, whereas $\mathrm{CD} 16^{-} \mathrm{CD} 49 \mathrm{~d}^{+}$granulocytes were eosinophils, we spotted freshly sorted cells onto glass slides that were stained with May-Grünwald-Giemsa.

Preparation of conditioned medium Peripheral blood from healthy donors was lysed and stained with APC-labelled anti-CD45 antibody (BD). Then, 100,000 cells of each population were seeded in $1 \mathrm{ml}$ of supplemented Endothelial Cell Growth Medium (PromoCell) and cultured in standard conditions $\left(5 \% \mathrm{CO}_{2} ; 37^{\circ} \mathrm{C}\right)$ for $16 \mathrm{~h}$. Conditioned medium samples were collected and centrifuged at $1000 \mathrm{~g}$ for $10 \mathrm{~min}$ to remove cell debris, and supernatants were collected to perform the tube formation assay.

Tubule formation assay HUVECs, passages 2-4, were cultured in supplemented endothelial growth medium (EGM, Lonza, Basel, Switzerland) on plastic and then transferred to 96-well plates coated with Matrigel. In this condition, within a few hours, cells organise in longitudinal tubes connected to each other. To test in vitro the activity of $\mathrm{CD}_{49} \mathrm{~d}^{+}$and $\mathrm{CD} 49 \mathrm{~d}^{-}$granulocytes, cells were freshly sorted with FACSAria (BD) based on the expression of CD49d in the granulocyte gate, labelled with PKH67 and co-incubated at a ratio of 1:12 (1250 CD49 $\mathrm{d}^{+/-}$cells and 15,000 HUVECs) with HUVECs for the tubule formation assay. After $24 \mathrm{~h}$ of incubation, cells were visualised under an inverted fluorescence microscope (IX71; Olympus, Tokyo, Japan). Tubule numbers, intersections and tubule length were quantified using ImageJ (Bethesda, MD, USA). In separated experiments, HUVECs were co-incubated at the same 1:12 ratio with granulocytes isolated from patients with diabetes or non-diabetic control individuals.

Spheroid sprouting assay For preparation of methocoel, $6 \mathrm{~g}$ of methylcellulose together with a magnetic stir bar were autoclaved in a $500 \mathrm{ml}$ flask. Then, $250 \mu \mathrm{l}$ of $60^{\circ} \mathrm{C}$ endothelial basal medium (EBM) was added under sterile conditions and the suspension was stirred at $60^{\circ} \mathrm{C}$ for $40 \mathrm{~min}$. Additional $250 \mathrm{ml}$ of EBM medium were added and the solution was stirred at $4^{\circ} \mathrm{C}$ overnight. Portions of $50 \mathrm{ml}$ of the solution were centrifuged for $2 \mathrm{~h}$ at $2500 \mathrm{~g}$ at room temperature. The highly viscose soluble fraction was separated from insoluble residue and was stored at $4{ }^{\circ} \mathrm{C}$. For the spheroid assay, 48,000 HUVECs were mixed with $6 \mathrm{ml}$ of methocoel and seeded as $100 \mu \mathrm{l}$ drops in a 96-well U-bottomed dish using a multipette. The cells were incubated for $24 \mathrm{~h}$ in an incubator to form spheroids. The following day, spheroids were collected and centrifuged and the spheroid pellet was mixed with methocoel mix. The collagen gel was prepared on ice and $500 \mu \mathrm{l}$ of collagen gel were added to the spheroid/methocoel solution, mixed by pipetting and seeded on a 24 -well culture dish for $30 \mathrm{~min}$ in an incubator. The spheroids were cultured for $24 \mathrm{~h}$ at $37^{\circ} \mathrm{C}$ and $5 \% \mathrm{CO}_{2}$ with $1500 \mathrm{CD} 49 \mathrm{~d}^{+}$or $\mathrm{CD} 49 \mathrm{~d}^{-}$ granulocytes labelled with PKH67 (green). Spheroids were finally fixed with formaldehyde. The sprouting area was quantified using ImageJ.

Gene expression in haematopoietic colonies During a previous study [20], we collected blood samples from diabetic and non-diabetic individuals before and $8 \mathrm{~h}$ after stimulation with the stem cell mobilising agent plerixafor. $\mathrm{CD} 34^{+}$stem cells from these samples were purified using the Diamond human CD34 isolation kit (Miltenyi Biotec) and 500 cells were plated on the Methocult colony forming assay (Stem Cells). At the end of the culture period, white colonies were manually picked-up and resuspended in QIAzol Lysis reagent for RNA isolation. cDNA was synthesised using SensiFAST cDNA Synthesis Kit (Bioline, London, UK) and qPCR was performed using SensiFAST SYBR Lo-ROX Kit (Bioline) via a QuantStudio 5 Real-Time PCR System (Thermo Fisher Scientific, MA, USA). PRG2 primers were: forward CCTGGTT TCCATCCACAACTTCAA; reverse TGCCGTCAACCCACTGAA.

Statistical analysis Continuous variables were reported as mean \pm SD if normal, unless otherwise specified, or as median (interquartile range) if not normal. Normality was checked using the Kolmogorov-Smirnov test. Non-normal variables were logtransformed (base 10) before statistical analysis with parametric tests. Categorical variables were reported as percentage. Comparison between two or more groups was performed using unpaired two-tailed Student's $t$ test or ANOVA, respectively. Categorical variables were compared using the $\chi^{2}$ test. The post hoc Bonferroni correction was applied. Intragroup comparisons (before/after) were performed using the paired two-tailed Student's $t$ test. Linear correlations were checked using the Pearson's $r$ coefficient. A multiple linear regression analysis was performed to evaluate the association between covariates, entered as a single block, and levels of PAGs as the dependent variable. Statistical significance was accepted for $p<0.05$. SPSS version 23.0 (IBM, USA) was used.

\section{Results}

Characterisation of human $C D 49 \mathrm{~d}^{+}$granulocytes We first characterised the phenotype of $\mathrm{CD} 49 \mathrm{~d}^{+}$granulocytes in humans (Fig. 1). We found that, among 46 healthy individuals, a discrete population of $\mathrm{CD} 49 \mathrm{~d}^{+}$granulocytes was always present (Fig. 1a,b), which represented $7.6 \pm 0.8 \%$ of the granulocyte gate, and was higher in men than in women $(9.3 \pm 1.3 \%$ vs $6.2 \pm 0.8 \%$; $p=0.046$; Fig. 1 c $)$. CD $49 \mathrm{~d}^{+}$cells in the polymorphonuclear cell gate, compared with $\mathrm{CD} 49 \mathrm{~d}^{+}$in the mononuclear cell gate, were positive for CD24, CD10, 

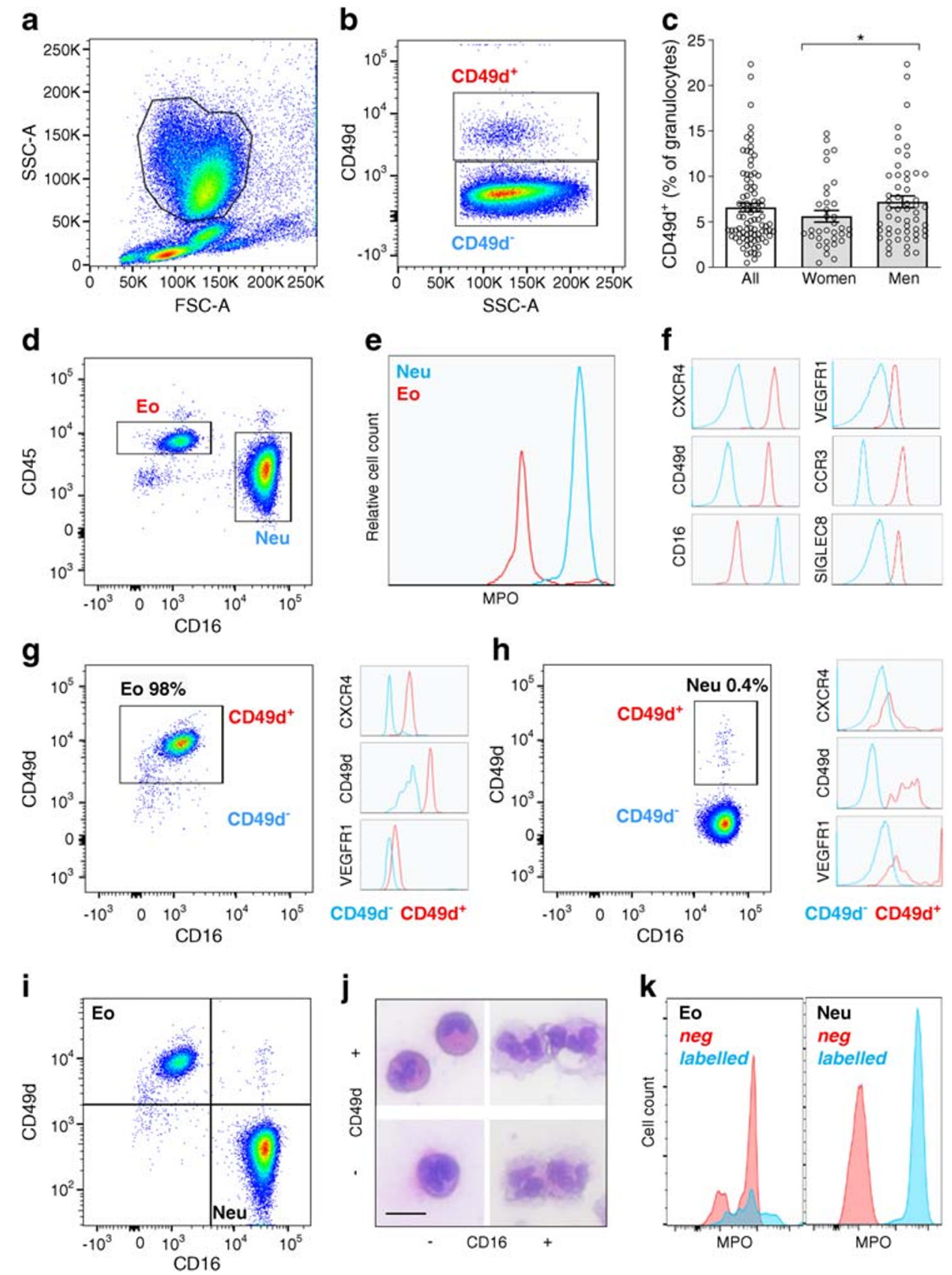

Fig. 1 Identification and quantification of PAGs by flow cytometry. We first gated granulocytes in the morphologic FSC-A vs SSC-A plot (a) and then examined the resulting population for expression of CD49d (b). Quantification of CD49d $\mathrm{d}^{+}$granulocytes in non-diabetic individuals is shown in $(\mathbf{c})$, stratified by sex $(* p<0.05)$. Within the granulocyte gate shown in (a), we then distinguished neutrophils from eosinophils in the CD16 vs CD45 gate (d). CD $16^{-} \mathrm{CD} 45^{\text {bright }}$ eosinophils and $\mathrm{CD} 16^{+} \mathrm{CD} 45^{+}$neutrophils defined antigenically were examined for intracellular expression of MPO (e) and for other markers: CXCR4, VEGFR1, CD49d, CCR3 and SIGLEC8 (f). Quantitative expression of CD49d was determined on $\mathrm{CD}^{-} 6^{-}$(g, eosinophils) and $\mathrm{CD}^{+} 6^{+}$(h, neutrophils) granulocytes; CXCR4 and VEGFR1 expression on CD49d ${ }^{+}$and CD49 $\mathrm{d}^{-}$fractions within the eosinophil and neutrophil populations is

CD15, CD66b, CD11b and negative for CD3 (T cells), CD19 (B cells), CD56 (NK cells) and CD14 (monocytes). Therefore, shown in the histograms in (g) and (h), respectively. (i) Identification of $\mathrm{CD} 4 \mathrm{~d}^{+}$eosinophils $\left(\mathrm{CD} 16^{-}\right)$and neutrophils $\left(\mathrm{CD} 16^{+}\right)$in the gate used to sort cells for subsequent May-Grünwald-Giemsa staining (j; scale bar $10 \mu \mathrm{m})$ : the typical bi-/tri-lobulated nucleus and pink cytoplasm confirmed eosinophil identity compared with the multi-lobulated nucleus and pale cytoplasm of neutrophils. (k) Intracellular MPO content was examined in gated CD16 ${ }^{-}$D $49 \mathrm{~d}^{+}$eosinophils and CD16 ${ }^{+} \mathrm{CD} 49 \mathrm{~d}^{+}$ neutrophils: although eosinophils showed the typical high autofluorescence, MPO-labelled cells showed no signal compared with the negative control, whereas neutrophils showed bright MPO signal compared with control. Histograms show mean and SEM, while circles indicate individual data points. Eo, eosinophils; Neu, neutrophils

CD $49 \mathrm{~d}^{+}$granulocytes were not contaminated by lymphomonocytes (ESM Fig. 1). 
Since CD49d has long been considered a marker of eosinophils [19], we checked whether CD49 $\mathrm{d}^{+}$granulocytes were eosinophils or neutrophils. Neutrophils and eosinophils were distinguished as being $\mathrm{CD} 16^{+} \mathrm{CD} 45^{+}$and $\mathrm{CD} 16^{-} \mathrm{CD} 45^{\text {bright }}$, respectively (Fig. 1d). As a confirmation of this immunephenotype, we found intracellular expression of MPO in gated neutrophils but not in eosinophils (Fig. 1e), whereas expression of CCR3 and SIGLEC8 confirmed the identity of $\mathrm{CD} 16^{-} \mathrm{CD} 45^{\text {bright }}$ as eosinophils (Fig. 1f). CD49d was expressed by the vast majority of eosinophils $(94.2 \pm 1.0 \%$; Fig. $1 \mathrm{~g})$ and by a small fraction of neutrophils $(1.1 \pm 0.3 \%$; Fig. 1h) Taking into account that eosinophils represented $\sim 5 \%$ of granulocytes, it appeared that the total CD $49 \mathrm{~d}^{+}$granulocyte population was composed of $>80 \%$ eosinophils and $<20 \%$ neutrophils (Fig. 1i). Analysis of May-Grünwald-Giemsa staining (Fig. 1j) and MPO intracellular content (Fig. 1k) confirmed that $\mathrm{CD}^{-} 6^{-}$granulocytes were eosinophils whereas $\mathrm{CD}_{16}{ }^{+}$granulocytes were neutrophils and that both subpopulations could be distinguished in CD49 $\mathrm{d}^{+}$and $\mathrm{CD} 49 \mathrm{~d}^{-}$cells.

We then compared CXCR4 and VEGFR1 expression on CD49d ${ }^{+}$vs CD49d $\mathrm{d}^{-}$cells separately in the CD16 ${ }^{-}$eosinophil and $\mathrm{CD} 16^{+}$neutrophil gates (Fig. 1g,h). Within the small fraction of $\mathrm{CD}_{4} 9 \mathrm{~d}^{+}$neutrophils, both CXCR4 and VEGFR1 expression was higher than in $\mathrm{CD}_{4} 9 \mathrm{~d}^{-}$neutrophils.
Expression of CXCR4 and VEGFR1 was also higher in $\mathrm{CD}_{49 \mathrm{~d}^{+}}$vs CD49d $\mathrm{d}^{-}$eosinophils. In general, expression of CXCR4 and VEGFR1 were higher in eosinophils ( $\sim 94 \%$ of which were $\left.\mathrm{CD} 49 \mathrm{~d}^{+}\right)$than in neutrophils $(\sim 98 \%$ of which were $\mathrm{CD} 4 \mathrm{~d}^{-}$) (Fig. 1f). These data highlight that, within the granulocyte population, CD49d identified cells with distinctive eosinophil or neutrophil characteristics, both of which expressed high levels of the proangiogenic markers CXCR4 and VEGFR1. Interestingly, the association between CD49d and CXCR4/VEGFR1 expression was not found in the mononuclear cell gate (ESM Fig. 2), suggesting that the proangiogenic antigenic phenotype associated with CD49d expression is specific for granulocytes.

In vitro angiogenic activity of human $\mathrm{CD} 4 \mathrm{~d}^{+}$granulocytes We employed two in vitro assays to evaluate the capacity of CD $49 \mathrm{~d}^{+}$granulocytes to support angiogenesis by human endothelial cells. CD49d $\mathrm{d}^{+}$or $\mathrm{CD} 49 \mathrm{~d}^{-}$granulocytes freshly sorted from healthy donors were mixed with endothelial cells in 2D Matrigel for tubule formation assay. Presence of CD $49 \mathrm{~d}^{+}$vs CD49d $\mathrm{d}^{-}$granulocytes significantly increased total tubule length, total number of tubules and tubule intersections (Fig. 2a,b; additional representative images in ESM Fig. 3a), while not affecting mean tube length. In separate experiments,

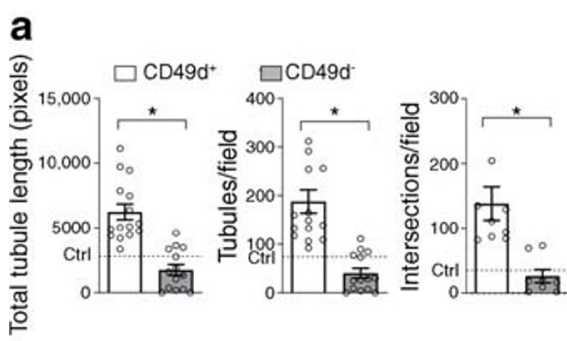

b
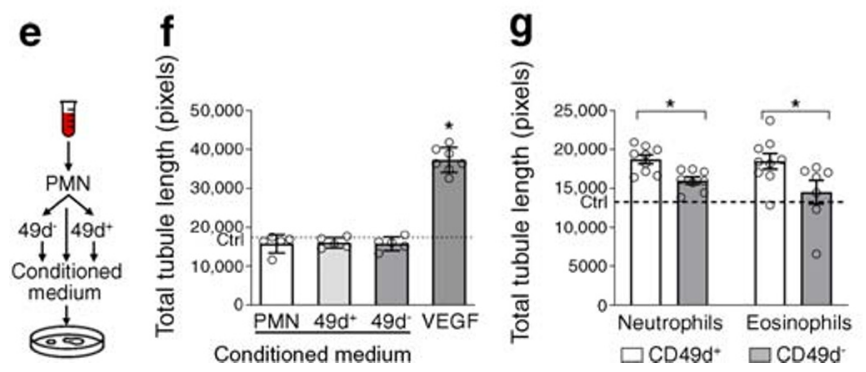

Fig. 2 Functional characterisation of CD49d ${ }^{+}$granulocytes. (a, b) Effects of co-incubation of $\mathrm{CD}^{4} 9 \mathrm{~d}^{+}$or CD49 $\mathrm{d}^{-}$granulocytes with HUVECs on total tubule length, number of tubules and intersections (a; * $p<0.05$ vs CD49d $\mathrm{d}^{-}$; the horizontal dashed line represents the negative control with unstimulated HUVECs). Representative images reconstructed from multiple fields are shown in (b) (additional replicates from the same experiment are shown in ESM Fig. 3a). (c, d) In separate experiments, CD49d ${ }^{+}$or CD49d granulocytes were labelled in green with PKH67 (c) and the proportion of green cells in the tubules, intersections or interspersed in the Matrigel were quantified (d; ${ }^{*} p$ $<0.05$ post-ANOVA; additional replicates from the same experiment are shown in ESM Fig. 3b). (e) Schematic representation of the experiment performed with conditioned media. (f) Total tube length formed by HUVECs in the presence of VEGF (as a positive control) or conditioned medium from unselected polymorphonuclear $(\mathrm{PMN})$ granulocytes, CD49 $\mathrm{d}^{+}$
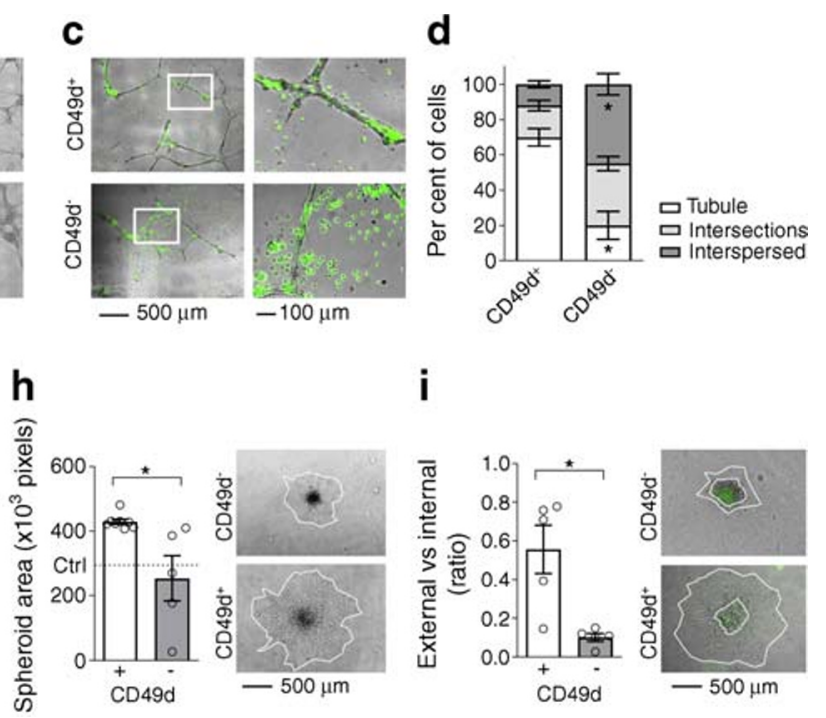

or CD49d $\mathrm{d}^{-}$granulocytes ${ }^{*} p<0.05$ vs the negative control of unstimulated HUVECs, represented by the dashed line). (g) Tube formation by HUVECs co-incubated with $\mathrm{CD}_{49} \mathrm{~d}^{+}$or $\mathrm{CD} 49 \mathrm{~d}^{-}$cells from the $\mathrm{CD}^{+} 6^{+}$neutrophil or CD16 eosinophil population $\left(* p<0.05\right.$ vs CD49d ${ }^{-}$; the negative control with unstimulated HUVECs is represented by the dashed line). (h) Effects of coincubation of CD49 $\mathrm{d}^{+}$or CD49d $\mathrm{d}^{-}$granulocytes with HUVECs on spheroid sprouting area; $* p<0.05$. In representative microphotographs, the sprouting area contour is shown. (i) In separate experiments, CD $49 \mathrm{~d}^{+}$or CD $49 \mathrm{~d}^{-}$ granulocytes were labelled in green with PKH67 and the ratio of green fluorescence in the core spheroid vs the sprouting area was compared $(* p<0.05)$. Histograms show mean and SEM, while circles indicate individual data points. In $(\mathbf{a}, \mathbf{b}, \mathbf{f})$ the horizontal dashed lines represent the negative control with unstimulated HUVECS 
CD49d $\mathrm{d}^{+}$or CD49d granulocytes were stained with the green fluorescent dye PKH67 to visualise their physical interactions with endothelial cells in the tubules (Fig. 2c; additional representative images in ESM Fig. 3b). While CD49d ${ }^{-}$ granulocytes were mainly interspersed in the Matrigel or located at tube intersections, $\mathrm{CD} 49 \mathrm{~d}^{+}$neutrophils were mainly located within tubules (Fig. 2d). This finding suggested that contact of CD49 $\mathrm{d}^{+}$cells with endothelial cells was needed for the proangiogenic effect. To support this hypothesis, we performed experiments with conditioned media from unselected granulocytes and $\mathrm{CD} 49 \mathrm{~d}^{+}$and $\mathrm{CD} 49 \mathrm{~d}^{-}$granulocytes, as illustrated in Fig. 2e. While tube length increased with a soluble positive control stimulus (VEGF), it did not change with any of the conditioned media (Fig. 2f). These data confirm that contact of granulocytes with endothelial cells is needed to exert the proangiogenic activity, possibly mediated by the adhesion molecule CD49d.

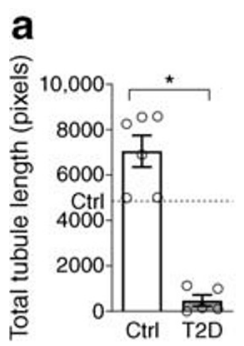

\section{b}

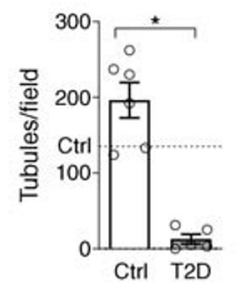

We then performed experiments to compare the in vitro proangiogenic potential of human $\mathrm{CD} 49 \mathrm{~d}^{+}$neutrophils vs CD $49 \mathrm{~d}^{+}$eosinophils. Cells were freshly sorted into $\mathrm{CD} 16^{+} \mathrm{CD} 49 \mathrm{~d}^{+/-}$neutrophils and $\mathrm{CD} 16^{-} \mathrm{CD} 49 \mathrm{~d}^{+/-}$eosinophils. Both within the $\mathrm{CD} 16^{+}$neutrophil and the $\mathrm{CD} 16^{-}$eosinophil populations, $\mathrm{CD} 49 \mathrm{~d}^{+}$cells supported tubule growth more than did CD49d ${ }^{-}$cells (Fig. 2g).

As a second in vitro angiogenesis model, we used the spheroid sprouting assay. CD49 $\mathrm{d}^{+}$or $\mathrm{CD} 49 \mathrm{~d}^{-}$granulocytes freshly sorted from healthy donors were mixed with endothelial cells, cultured as hanging drops to form spheroids, and embedded in a 3D collagen matrix. The sprouting area at $24 \mathrm{~h}$ was significantly higher when endothelial cells were co-cultured with $\mathrm{CD} 49 \mathrm{~d}^{+}$than with $\mathrm{CD} 49 \mathrm{~d}^{-}$granulocytes (Fig. 2h). In separate experiments, CD49d $\mathrm{d}^{+}$or $\mathrm{CD} 49 \mathrm{~d}^{-}$ granulocytes were stained with the fluorescent dye PKH67 to visualise physical interactions with endothelial cells in the
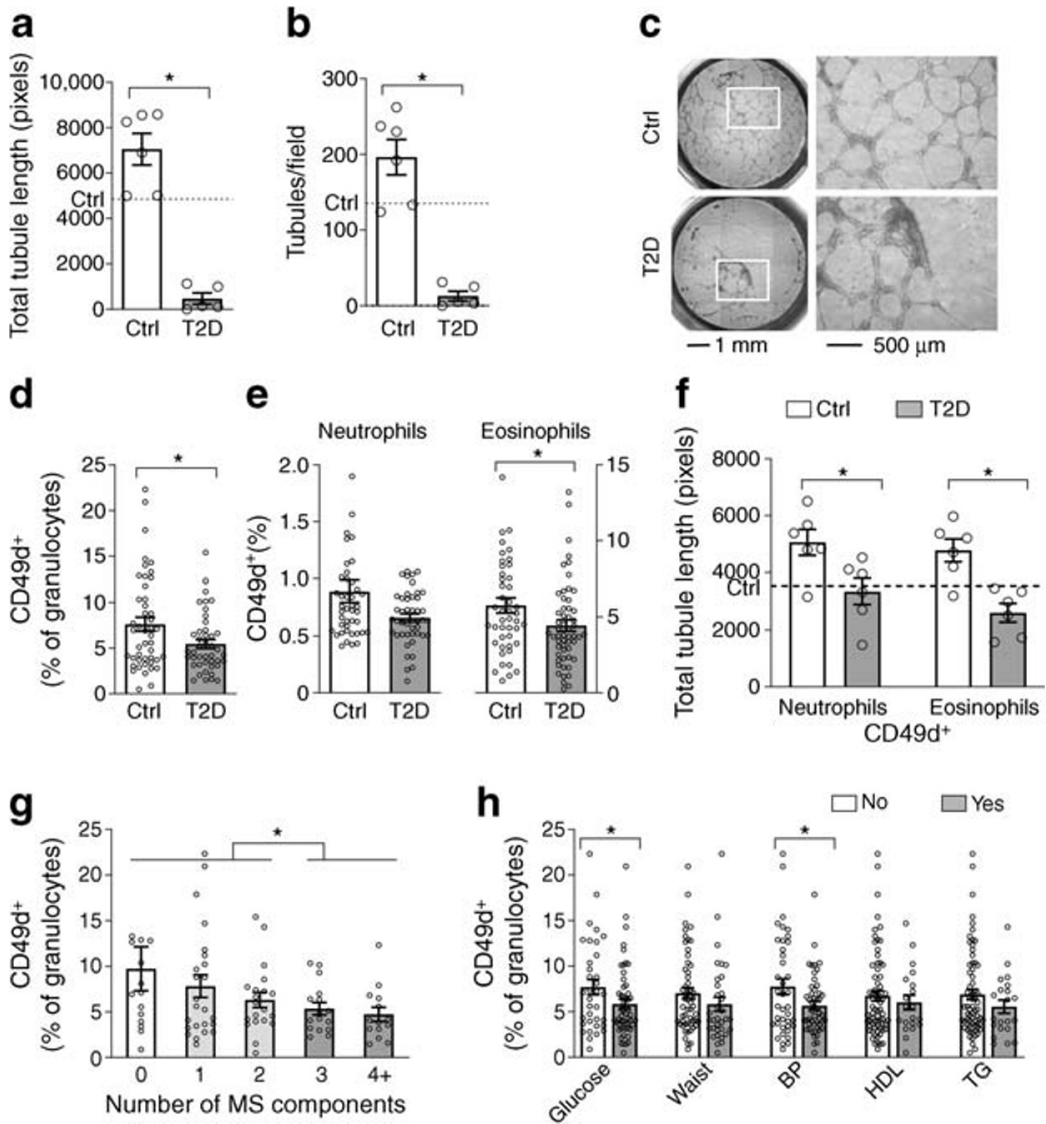

Fig. 3 PAGs in type 2 diabetes. (a, b) Tubule formation (total tubule length and tubule numbers) by endothelial cells co-incubated with granulocytes isolated from patients with (T2D) and without (Ctrl) type 2 diabetes; $* p<0.05$. (c) Representative images reconstructed from multiple fields of the tubule formation assay in the two conditions (additional replicates from the same experiment are shown in ESM Fig. 3c). (d) Levels of CD $49 \mathrm{~d}^{+}$PAGs in T2D vs Ctrl $(* p<0.05)$. (e) Levels of CD $49 \mathrm{~d}^{+}$expression in T2D vs Ctrl in the eosinophil and neutrophil populations; $* p<0.05$. (f) Tubule formation assay by endothelial cells coincubated with $\mathrm{CD} 49 \mathrm{~d}^{+}$neutrophils or eosinophils freshly sorted from diabetic and non-diabetic patients $(* p<0.05)$. (g) Levels of CD $49 \mathrm{~d}^{+}$

PAGs in the entire cohort of T2D and Ctrl participants stratified by the number of metabolic syndrome (MS) components: in addition to confirming significance of the linear tendency, we tested the difference between patients with and without the metabolic syndrome $\left({ }^{*} p<0.05\right)$. (h) Study participants were also stratified according to the presence or absence of each metabolic syndrome component (Glucose, fasting plasma glucose $>5.5 \mathrm{mmol} / 1$; Waist, waist circumference $>102 \mathrm{~cm}$ for men or $>88 \mathrm{~cm}$ for women; BP, raised BP; HDL, low HDL-cholesterol; TG, high triacylglycerol); $* p<0.05$. Histograms show mean and SEM, while circles indicate individual data points. In $(\mathbf{a}, \mathbf{b}, \mathbf{f})$ the horizontal dashed lines represent the negative control with unstimulated HUVECs 
Table 1 Clinical characteristics of type 2 diabetic vs non-diabetic participants

\begin{tabular}{|c|c|c|c|}
\hline Characteristic & $\begin{array}{l}\text { Non- } \\
\text { diabetic }\end{array}$ & Type 2 diabetes & $p$ value \\
\hline Age, years & $57.7 \pm 8.4$ & $58.1 \pm 12.9$ & 0.863 \\
\hline Sex, male, $\%$ & 46 & 77 & 0.002 \\
\hline BMI, $\mathrm{kg} / \mathrm{m}^{2}$ & $26.4 \pm 4.8$ & $30.8 \pm 5.5$ & $<0.001^{*}$ \\
\hline Diabetes duration, years & - & $10.4 \pm 8.4$ & - \\
\hline Fasting plasma glucose, mmol/1 & $5.2 \pm 0.4$ & $8.6 \pm 2.5$ & $<0.001^{*}$ \\
\hline $\mathrm{HbA}_{1 \mathrm{c}}, \mathrm{mmol} / \mathrm{mol}$ & $38 \pm 3$ & $63 \pm 14$ & $<0.001^{*}$ \\
\hline $\mathrm{HbA}_{1 \mathrm{c}}, \%$ & $5.6 \pm 0.3$ & $7.9 \pm 1.3$ & \\
\hline Hypertension, \% & 37 & 77 & $<0.001 *$ \\
\hline Active smoking, $\%$ & 36 & 37 & 0.929 \\
\hline Total cholesterol, mmol/1 & $5.2 \pm 1.0$ & $4.8 \pm 1.2$ & 0.067 \\
\hline HDL-cholesterol, mmol/1 & $1.5 \pm 0.5$ & $1.2 \pm 0.3$ & $<0.001 *$ \\
\hline LDL-cholesterol, mmol/1 & $3.1 \pm 0.9$ & $2.7 \pm 0.8$ & 0.030 \\
\hline Triacylglycerol, mmol/1 & $1.2 \pm 0.5$ & $2.1 \pm 3.4$ & 0.078 \\
\hline White blood cells, $n / \mu l$ & $5968 \pm 1248$ & $7082 \pm 1531$ & $<0.001 *$ \\
\hline \multicolumn{4}{|l|}{ Complications } \\
\hline Retinopathy, \% & 0 & 24 & 0.010 \\
\hline Neuropathy, \% & 0 & 14 & 0.058 \\
\hline Urinary ACR, mg/mmol & $1.2 \pm 2.0$ & $8.8 \pm 2.6$ & 0.322 \\
\hline Urinary ACR, mg/g & $10.3 \pm 17.8$ & $78.2 \pm 233.4$ & \\
\hline Serum creatinine, $\mu \mathrm{mol} / 1$ & $70 \pm 9$ & $70 \pm 18$ & 0.682 \\
\hline Nephropathy, \% & 4 & 29 & 0.019 \\
\hline Coronary artery disease, $\%$ & 9 & 10 & 0.914 \\
\hline Cerebrovascular disease, $\%$ & 39 & 31 & 0.513 \\
\hline Peripheral arterial disease, $\%$ & 2 & 13 & 0.090 \\
\hline \multicolumn{4}{|l|}{ Therapies } \\
\hline Metformin, \% & 0 & 79 & $<0.001$ \\
\hline Sulfonylurea, $\%$ & 0 & 14 & 0.010 \\
\hline DPP-4 inhibitors, $\%$ & 0 & 7 & 0.076 \\
\hline GLP-1 receptor agonists, $\%$ & 0 & 5 & 0.151 \\
\hline Insulin, \% & 0 & 37 & $<0.001^{*}$ \\
\hline ACEi/ARBs, \% & 20 & 65 & $<0.001^{*}$ \\
\hline$\beta$-blockers, $\%$ & 11 & 19 & 0.349 \\
\hline Other BP lowering therapies, $\%$ & 18 & 44 & 0.008 \\
\hline Anti-platelet therapy, $\%$ & 18 & 30 & 0.193 \\
\hline Statins, $\%$ & 50 & 58 & 0.452 \\
\hline
\end{tabular}

Data are expressed as mean $\pm \mathrm{SD}$ or as percentage

* Statistically significant $(p<0.05)$ after adjusting for multiple testing

ACEi, ACE inhibitor; ARB, angiotensin receptor blocker; DPP-4, dipeptidyl peptidase-4; GLP-1, glucagon-like peptide-1

sprouts. While the majority of CD49 $\mathrm{d}^{-}$granulocytes remained trapped in the endothelial cell spheroid, CD49d $\mathrm{d}^{+}$granulocytes were often located in the sprouting area. As a result, the ratio between the fluorescence found in the sprouting over that found in the spheroid was significantly higher for CD49d $\mathrm{d}^{+}$

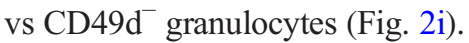

These assays suggest that $\mathrm{CD} 49 \mathrm{~d}^{+}$granulocytes support in vitro angiogenesis possibly by physically interacting with endothelial cells. Altogether, antigenic and functional characterisation identified $\mathrm{CD} 49 \mathrm{~d}^{+}$in the polymorphonuclear gate as PAGs.

PAGs in type 2 diabetes We evaluated whether in vitro endothelial cell tubule formation was differentially affected by the presence of granulocytes isolated from male participants with or without type 2 diabetes. Isolated granulocytes contained PAGs normally distributed in $\mathrm{CD} 16^{+} \mathrm{CD} 49 \mathrm{~d}^{+}$neutrophils and $\mathrm{CD} 16^{-} \mathrm{CD} 49 \mathrm{~d}^{+}$eosinophils (ESM Fig. 4). In the presence 
of granulocytes from diabetic individuals, endothelial cells formed significantly fewer tubules, with a reduced total tubule length (Fig. 3a,b; additional representative images in ESM Fig. 3c). This suggested that granulocytes from diabetic individuals were less able to support angiogenesis. Since the proangiogenic activity of granulocytes was confined to the CD $49 \mathrm{~d}^{+}$fraction (Fig. 3), we hypothesised that reduced support of angiogenesis by diabetic granulocytes could be due to a quantitative defect in CD49d ${ }^{+}$cells. We thus compared the levels of CD49 $\mathrm{d}^{+}$PAGs in diabetic vs nondiabetic participants (Fig. 3d,e; cohort baseline data in Table 1). The percentage of CD49 $\mathrm{d}^{+}$granulocytes was significantly lower in diabetic than in non-diabetic patients $(5.5 \pm$ $0.5 \%$ vs $7.6 \pm 0.8 \% ; p=0.021$; Fig. $3 \mathrm{~d})$. CD $49 \mathrm{~d}^{+}$cells were reduced proportionally within the neutrophil and eosinophil populations relative to the total granulocyte gate, but it was statistically significant only within eosinophils (Fig. 3e). CD49d $\mathrm{d}^{+}$PAG levels were also reduced in diabetic vs control participants when expressed in absolute terms, $(186 \pm 11$ vs $239 \pm 14$ cells $/ \mu \mathrm{l} ; p=0.046)$. However, the profoundly impaired tube forming capacity of diabetic granulocytes could only be partially explained by quantitative PAG reduction. Thus, we compared tube forming capacity of endothelial cells

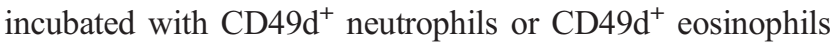
freshly isolated from the blood of sex-matched diabetic and non-diabetic participants. Within both neutrophils and eosinophils, diabetic CD49 $\mathrm{d}^{+}$PAGs were unable to increase endothelial cell tube formation (Fig. 3f), suggesting that diabetes induces both quantitative and functional impairment of PAGs.

As expected, type 2 diabetic patients had a higher BMI, lower HDL-cholesterol, and higher prevalence of hypertension than non-diabetic control individuals (Table 1). Upon a multiple regression analysis adjusted for significant differences between the two groups, the inverse association between type 2 diabetes and level of $\mathrm{CD}_{49} \mathrm{~d}^{+}$granulocytes remained significant but was attenuated (Table 2). Thus, we

Table 2 Results of the multivariable analysis

\begin{tabular}{lrc}
\hline Covariate & $\mathrm{B} \pm \mathrm{SE}$ & $p$ value \\
\hline Diabetes (vs non-diabetes) & $-2.2 \pm 1.1$ & 0.041 \\
Sex, male & $3.1 \pm 1.0$ & 0.004 \\
BMI & $-0.1 \pm 0.1$ & 0.326 \\
Hypertension & $-2.0 \pm 1.3$ & 0.116 \\
HDL-cholesterol & $-0.1 \pm 0.1$ & 0.729 \\
ACEi / ARBs & $0.6 \pm 1.4$ & 0.686 \\
Other blood pressure lowering drugs & $-0.1 \pm 1.3$ & 0.944 \\
\hline
\end{tabular}

The dependent variable was the level of CD49d $\mathrm{d}^{+}$neutrophils

The regression coefficient $\mathrm{B}$, its standard error (SE) and $p$ values are reported for each covariate in the model

$\mathrm{ARB}$, angiotensin receptor blocker hypothesised that part of the reduction in PAGs observed in type 2 diabetes may be attributable to concomitant risk factors that define the metabolic syndrome. Indeed, the level of PAGs progressively and linearly declined with increasing number of metabolic syndrome components (Fig. 3g) and there were significant reductions in the levels of $\mathrm{CD} 49 \mathrm{~d}^{+}$granulocytes with the glucose and blood pressure component of the metabolic syndrome (Fig. 3h).

Since most eosinophils express CD49d and diabetes reduced total $C D 49 \mathrm{~d}^{+}$granulocytes, a reduction in the total eosinophil population was expected. The total white blood cell count was mildly elevated in type 2 diabetes (ESM Fig. 5a), with an imbalance in the granulocyte-to-lymphocyte ratio (ESM Fig. 5b,c), typical of enhanced myelopoiesis [21]. Data obtained using an automated cell counter showed that diabetic participants had a significant relative increase in neutrophils and no significant difference in eosinophils. Using flow cytometry (ESM Fig. 5d,e), diabetic patients displayed an increase in the percentage of $\mathrm{CD} 16^{+} \mathrm{CD} 45^{+}$ neutrophils and a decrease in $\mathrm{CD} 16^{-} \mathrm{CD} 45^{\text {bright }}$ eosinophils (which were $\mathrm{CCR}^{+}{ }^{+}$and SIGLEC ${ }^{+}$, Fig. 1f).

Impact of hyperglycaemia on PAGs In type 2 diabetes, an inverse correlation was observed between PAG levels and fasting plasma glucose (Fig. 4a) but not $\mathrm{HbA}_{1 \mathrm{c}}$, which was not surprising in view of the short half-life of human granulocytes (from hours to a few days). To better understand the direct effect of hyperglycaemia on PAGs, we quantified CD $49 \mathrm{~d}^{+}$granulocytes in ten type 2 diabetic patients before and after 12 weeks of treatment with the SGLT2 inhibitor dapagliflozin. Clinical characteristics of enrolled patients are shown in ESM Table 2. $\mathrm{HbA}_{1 \mathrm{c}}$ declined from $67 \pm 2 \mathrm{mmol} /$ $\mathrm{mol}(8.3 \pm 0.2 \%)$ to $56 \pm 2 \mathrm{mmol} / \mathrm{mol}(7.3 \pm 0.3 \%) ; 8$ of 10 patients displayed an increase in their levels of PAGs and the mean cell level significantly increased 1.8-times from baseline to 12 weeks (Fig. 4b). Next, we examined levels of PAGs in 15 patients with type 1 diabetes, and in 15 healthy controls of similar age and sex (ESM Table 3). Similarly to what was observed in patients with type 2 diabetes, type 1 diabetes was also associated with a significant reduction of CD49d ${ }^{+}$granulocytes (Fig. 4c). Finally, to address an even cleaner model, we quantified CD49d $\mathrm{d}^{+}$granulocytes in STZinduced type 1-like diabetic mice vs non-diabetic control mice. This model is characterised by marked hyperglycaemia in the absence of dyslipidaemia (ESM Table 4) and is ideally suitable to evaluate the isolated effects of high glucose. Murine neutrophils and eosinophils were distinguished by expression of Ly6G and SIGLEC-F (Fig. 4d-i), ruling out monocyte contamination by CD115 staining (Fig. 4f,j). As observed in humans, CD49d labelled a small fraction of neutrophils and the majority of eosinophils (Fig. 4f,j). Within both neutrophils (Fig. 4g) and eosinophils (Fig. 4k), CD49d ${ }^{+}$cells had higher MFI of VEGFR1 and CXCR4 


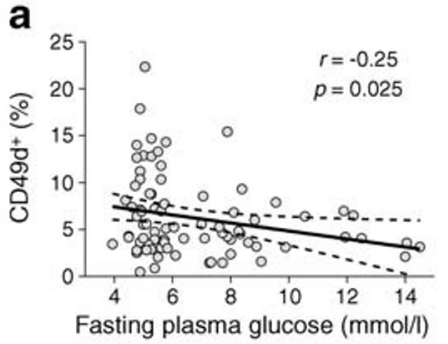

d

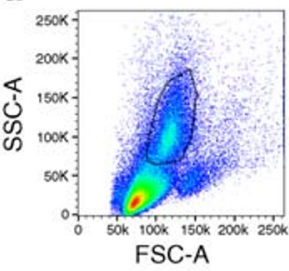

e

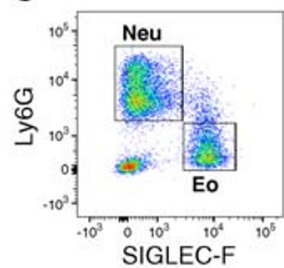

h

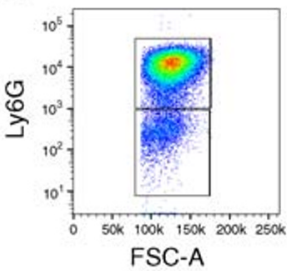

i

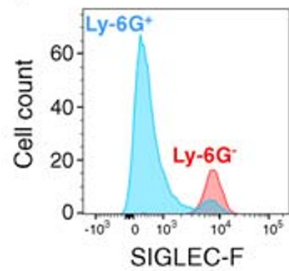

b

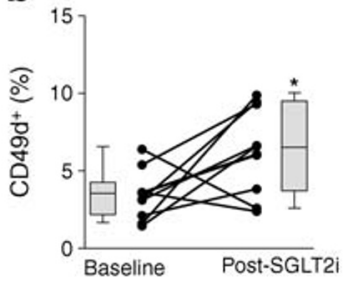

f

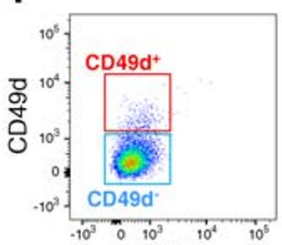

CD115

j

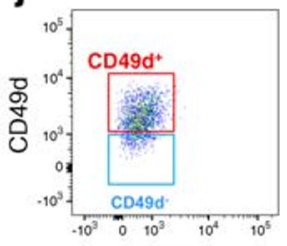

CD115

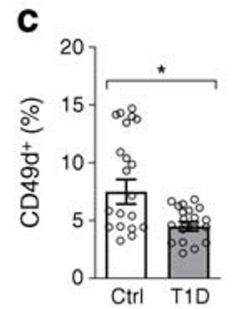

g

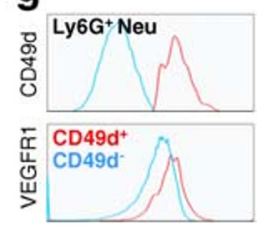

k

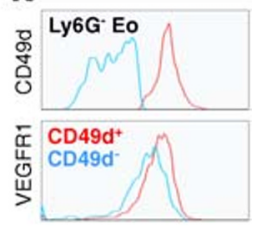

(a)
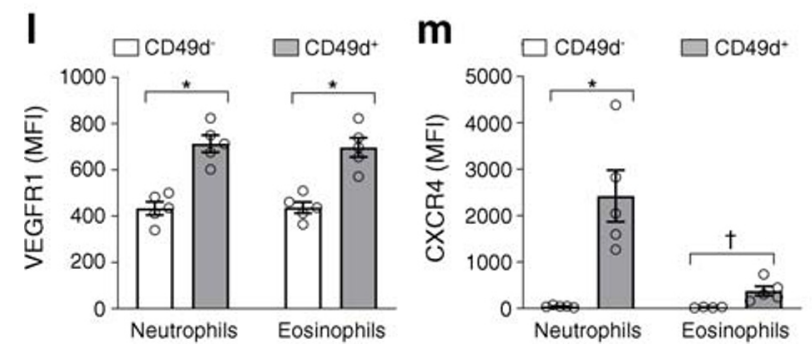

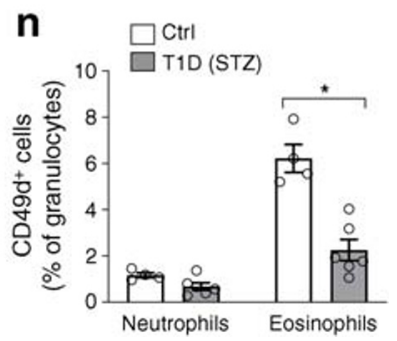

Fig. 4 Effects of hyperglycaemia on PAGs. (a) Levels of CD49d ${ }^{+}$PAGs were correlated with fasting plasma glucose; the regression coefficient $r$ and the corresponding $p$ values are shown. (b) Levels of CD49d $\mathrm{d}^{+}$PAGs were quantified at baseline and after 12 weeks of treatment with the SGLT2 inhibitor (SGLT2i) dapagliflozin. The box shows median and interquartile range, whereas whiskers indicate full range and lines indicate individual patients; $* p<0.05$. (c) Levels of CD $49 \mathrm{~d}^{+}$PAGs were compared in type 1 diabetic (T1D) participants vs non-diabetic control (Ctrl) participants $(* p<0.05)$. (d--k) Identification and characterisation of murine PAGs: granulocytes were first gated in the morphologic FSC-A vs SSC-A plot (d) and the resulting population was analysed for expression of the granulocyte marker Ly6G (h); expression of CD49d was analysed

(Fig. 4l,m), consistent with a proangiogenic capacity. Type 1like diabetes in mice led to a significant reduction in CD49d expression among both neutrophils and eosinophils, which was significant for eosinophils compared with non-diabetic control mice (Fig. 4n).

Potential mechanisms of CD49 $\mathrm{d}^{+}$cell defect in diabetes Since a general CD49d downregulation was observed in diabetes and in view of the emerging effect of hyperglycaemia on PAGs, we examined whether exposing granulocytes to high on the $\mathrm{Ly}_{6 \mathrm{G}}{ }^{+}$neutrophil and $\mathrm{Ly}_{6} \mathrm{G}^{-}$eosinophil population (e), both excluding monocytic contamination using CD115 (f, j). Eosinophil identity of Ly6G $6 \mathrm{G}^{-}$granulocytes was confirmed by SIGLEC-F staining (i). Resulting $\mathrm{Ly}_{6} \mathrm{G}^{+} \mathrm{CD} 49 \mathrm{~d}^{+}$neutrophils (f, g) and $\mathrm{Ly}_{6} \mathrm{G}^{-} \mathrm{CD} 49 \mathrm{~d}^{+}$eosinophils $(\mathbf{j}, \mathbf{k})$ were examined for expression of CXCR4 and VEGFR1, relative to the respective CD49d $\mathrm{d}^{-}$controls. (I, m) Quantification of VEGFR1 and CXCR4 MFI, respectively, on CD49d ${ }^{+}$vs CD49d neutrophils and eosinophils ( ${ }^{*} p<0.05$ vs $\mathrm{CD} 49 \mathrm{~d}^{-} ;{ }^{\dagger} p=0.08$ vs $\left.\mathrm{CD}^{\dagger} 9 \mathrm{~d}^{-}\right)$. (n) Comparison of the levels of total CD49d ${ }^{+}$PAGs in diabetic (T1D) mice vs non-diabetic control (Ctrl) mice; $* p<0.05$. Histograms show mean and SEM, while circles indicate individual data points. Eo, eosinophils; Neu, neutrophils

glucose ex vivo resulted in a reduction of CD49d expression. We performed a short-term experiment in high glucose and high-mannitol (osmotic control) because granulocytes are short-lived. Exposure to $20 \mathrm{mmol} / 1$ glucose or mannitol for $18 \mathrm{~h}$, compared with the control unstimulated condition, did not significantly modify CD49d expression (ESM Fig. 6), thereby ruling out that high glucose directly reduced CD49d expression on granulocytes.

To explore whether defective generation of CD $49 \mathrm{~d}^{+}$cells, most of which are eosinophils, is part of the disturbed 
myelopoiesis associated with diabetes [21], we analysed gene expression of haematopoietic colonies generated in a previous study before and after $\mathrm{CD} 34^{+}$stem cell mobilisation with plerixafor [20]. Colonies from diabetic participants, compared with control participants, expressed lower levels of the $P R G 2$ gene, which encodes the eosinophil-specific marker major basic protein (ESM Fig. 7).

\section{Discussion}

In this study, we describe shortage and dysfunction of circulating PAGs in patients with diabetes, reflecting a diminished activity of granulocytes in support of angiogenesis. Solid data also point to a direct role of hyperglycaemia in the reduction of PAGs observed in diabetic patients.

Proangiogenic neutrophils have been previously described in mice as $\mathrm{Ly}_{6} \mathrm{G}^{+}$neutrophils expressing $\mathrm{CD} 49 \mathrm{~d}$ and enriched in surface VEGFR1 and CXCR4 [14]. In vivo, expression of VEGFR1 on neutrophils and of VEGFR2 on endothelial cells was required for recruitment of neutrophils to tissues stimulated with VEGF-A [14]. Neutrophil emigration was completely abolished by neutralisation of the adhesion molecule CD49d, suggesting that cell adhesion by CD49d was required for the proangiogenic function. A similar population of $\mathrm{CD} 49 \mathrm{~d}^{+}$neutrophils in the human peripheral blood accounted for $\sim 3.2 \%$ of neutrophils [14]. We herein confirmed existence of human $\mathrm{CD} 16^{+} \mathrm{CD} 49 \mathrm{~d}^{+}$neutrophils, accounting for $\sim 1 \%$ of neutrophils, and characterised by high expression of CXCR4 and VEGFR1. Intriguingly, however, based on immune-phenotype, granule content and cytology, most $(>80 \%)$ CD $49 \mathrm{~d}^{+}$granulocytes proved to be eosinophils. Similar to CD49 $\mathrm{d}^{+}$neutrophils, CD49 $\mathrm{d}^{+}$eosinophils also expressed high levels of CXCR4 and VEGFR1. Since CD $49 \mathrm{~d}^{+}$eosinophils and neutrophils were equally supportive of endothelial cell tube formation, the proangiogenic activity of $\mathrm{CD} 49 \mathrm{~d}^{+}$granulocytes was not confined to the neutrophil population. Eosinophils have long been implicated in angiogenesis, especially in cancer [22] and in allergic asthma [23, 24]. Thereafter, we focused on the total population of CD $49 \mathrm{~d}^{+}$ granulocytes, including both eosinophils and neutrophils. Using $2 \mathrm{D}$ and $3 \mathrm{D}$ angiogenesis assays, we demonstrate the in vitro functional properties of human $\mathrm{CD} 49 \mathrm{~d}^{+}$granulocytes, allowing us to use the term proangiogenic granulocytes (PAGs). Cell-tracking experiments revealed location of CD49d ${ }^{+}$granulocytes close to endothelial cells in the tubules and in the sprouts, suggesting that physical interactions between granulocytes and endothelial cells are important in driving the proangiogenic effect. This is in agreement with the role of CD49d in adhesion of leucocytes to the endothelium and is supported by our observation that conditioned medium did not recapitulate the tube-supporting effect of $\mathrm{CD} 49 \mathrm{~d}^{+}$ granulocytes.
On the basis of the established notion that diabetes impairs angiogenesis [25], we explored PAGs in diabetic patients. First, we found that granulocytes from type 2 diabetic patients were less able to support in vitro tubule formation by endothelial cells, when compared with granulocytes from nondiabetic control individuals. Since we had noted that CD $49 \mathrm{~d}^{+}$granulocytes stimulated tubule formation more than CD $49 \mathrm{~d}^{-}$granulocytes, we hypothesised that the proangiogenic defect of granulocytes from diabetic individuals could be attributed to reductions in $\mathrm{CD} 49 \mathrm{~d}^{+}$cells. Indeed, levels of PAGs were $\sim 30 \%$ lower in type 2 diabetic vs control participants. Quantitative reduction of diabetic PAGs, together with their inability to support endothelial tube formation, explained the profoundly impaired proangiogenic function of diabetic granulocytes.

An inverse correlation was observed between glucose and PAG levels, implying a possible role of glucotoxicity. However, the effects of hyperglycaemia in type 2 diabetes could hardly be dissected from those of concomitant risk factors. Adjusting for variables that differed between the two groups, diabetes remained associated with lower PAGs. To better evaluate the direct impact of hyperglycaemia, we quantified PAGs in a subgroup of type 2 diabetic patients before and after a 12-week therapy with the SGLT2 inhibitor dapagliflozin. Interestingly, glucose control achieved with dapagliflozin was associated with a rise in the levels of PAGs. Since SGLT2 inhibitors exert their glucose-lowering action independently from insulin and exclusively by inducing urinary glucose excretion [26], this setting is ideal to demonstrate the impact of glucotoxicity. In further support of a role for hyperglycaemia in PAG reduction, we found that type 1 diabetic patients without cardiovascular or renal complications had lower levels of PAGs when compared with control individuals of similar age and sex. Finally, we quantified PAG levels in STZ-induced type 1-like diabetic mice, the prototypical murine model of hyperglycaemia. PAGs were significantly lower in diabetic vs non-diabetic control mice. While experimental data suggest that high glucose does not accelerate atherogenesis independently from other risk factors [27], people with type 1 diabetes experience an increased risk of cardiovascular events compared with non-diabetic people [28] and intensive glucose control exerts cardiovascular protection against CVD in type 1 diabetes [29]. Altogether, our results point to a direct role for hyperglycaemia in the reduction of PAGs observed in type 1 and type 2 diabetes, which is, however, not mediated by downregulation of CD49d in high glucose. Pauperisation of CD49d $\mathrm{d}^{+}$ granulocytes in diabetic patients was associated with significantly reduced levels of the total immune-defined eosinophil pool. Since hyperglycaemia has been shown to induce myeloid bias [21, 30], we speculated that a reduction of PAGs and eosinophils resulted from a skewed differentiation of haematopoietic precursors. Preliminary results showed an 
impaired generation of eosinophils from diabetic haematopoietic stem cells. Interestingly, since eosinophils belong to Th2 innate immune function [31], a general imbalance between Th1 (neutrophils and M1 macrophages) and Th2 (eosinophils and M2 macrophages) may mark a disturbed immuno-metabolic crosstalk.

In conclusion, our data add mechanistic information to explain the impairment of angiogenesis in diabetes and broaden the variety of blood cell types involved in diabetic vascular disease. Future studies will enable us to expand our knowledge on the role of PAGs in chronic diabetic vascular complications.

Data availability Original data are available from the corresponding author at a reasonable request.

Funding The study was supported by grants from: the Italian Ministry of University and Education to GPF (PRIN 2015ZTT5KB); the European Foundation for the Study of Diabetes (EFSD) / Lilly 2016 grant to GPF; the Italian Diabetes Society / Lilly 2017 grant to GPF; the Italian Ministry of Health (RF-2013-02358024) to MA. The study funders were not involved in the design of the study; the collection, analysis, and interpretation of data; writing the report; and did not impose any restrictions regarding the publication of the report.

Authors' relationships and activities The authors declare that there are no relationships or activities that might bias, or be perceived to bias, their work.

Contribution statement RC, MDA, MA, AA and GPF designed the study, RC, MDA, LM, BMB, MA acquired the data, RC, MDA, LM and GPF drafted the manuscript. BMB, MA and AA revised the manuscript. All authors approved the final version of the manuscript. GPF is the guarantor of this work.

\section{References}

1. Rao Kondapally Seshasai S, Kaptoge S, Thompson A et al (2011) Diabetes mellitus, fasting glucose, and risk of cause-specific death. N Engl J Med 364(9):829-841. https://doi.org/10.1056/ NEJMoa1008862

2. Fadini GP, Cosentino F (2018) Diabetes and ischaemic stroke: a deadly association. Eur Heart J 39(25):2387-2389. https://doi.org/ 10.1093/eurheartj/ehy033

3. Capes SE, Hunt D, Malmberg K, Gerstein HC (2000) Stress hyperglycaemia and increased risk of death after myocardial infarction in patients with and without diabetes: a systematic overview. Lancet 355(9206):773-778. https://doi.org/10.1016/S01406736(99)08415-9

4. Aguilar D, Solomon SD, Kober L et al (2004) Newly diagnosed and previously known diabetes mellitus and 1-year outcomes of acute myocardial infarction: the VALsartan In Acute myocardial iNfarcTion (VALIANT) trial. Circulation 110(12):1572-1578. https://doi.org/10.1161/01.CIR.0000142047.28024.F2

5. Fadini GP, Spinetti G, Santopaolo M, Madeddu P (2019) Impaired regeneration contributes to poor outcomes in diabetic peripheral artery disease. Arterioscler Thromb Vasc Biol 40(1):34-44

6. Fadini GP, Albiero M, Bonora BM, Avogaro A (2019) Angiogenic abnormalities in diabetes mellitus: mechanistic and clinical aspects.
J Clin Endocrinol Metab 104(11):5431-5444. https://doi.org/10. 1210/jc.2019-00980

7. Howangyin KY, Silvestre JS (2014) Diabetes mellitus and ischemic diseases: molecular mechanisms of vascular repair dysfunction. Arterioscler Thromb Vasc Biol 34(6):1126-1135. https://doi.org/ 10.1161/ATVBAHA.114.303090

8. Fadini GP, Rigato M, Cappellari R, Bonora BM, Avogaro A (2017) Long-term prediction of cardiovascular outcomes by circulating CD34+ and CD34+CD133+ stem cells in patients with type 2 diabetes. Diabetes Care 40(1):125-131. https://doi.org/10.2337/ dc16-1755

9. Fadini GP, Ciciliot S, Albiero M (2017) Concise review: perspectives and clinical implications of bone marrow and circulating stem cell defects in diabetes. Stem Cells 35(1):106-116. https://doi.org/ 10.1002/stem. 2445

10. Fadini GP, de Kreutzenberg SV, Boscaro E et al (2013) An unbalanced monocyte polarisation in peripheral blood and bone marrow of patients with type 2 diabetes has an impact on microangiopathy. Diabetologia 56(8):1856-1866. https://doi.org/10.1007/s00125013-2918-9

11. Jetten N, Verbruggen S, Gijbels MJ, Post MJ, De Winther MP, Donners MM (2014) Anti-inflammatory M2, but not proinflammatory M1 macrophages promote angiogenesis in vivo. Angiogenesis 17(1):109-118. https://doi.org/10.1007/s10456-0139381-6

12. Nozawa H, Chiu C, Hanahan D (2006) Infiltrating neutrophils mediate the initial angiogenic switch in a mouse model of multistage carcinogenesis. Proc Natl Acad Sci U S A 103(33):1249312498. https://doi.org/10.1073/pnas.0601807103

13. Gaudry M, Bregerie O, Andrieu V, El Benna J, Pocidalo MA, Hakim J (1997) Intracellular pool of vascular endothelial growth factor in human neutrophils. Blood 90(10):4153-4161

14. Massena S, Christoffersson G, Vagesjo E et al (2015) Identification and characterization of VEGF-A-responsive neutrophils expressing CD49d, VEGFR1, and CXCR4 in mice and humans. Blood 126(17):2016-2026. https://doi.org/10.1182/blood-2015-03631572

15. Friedewald WT, Levy RI, Fredrickson DS (1972) Estimation of the concentration of low-density lipoprotein cholesterol in plasma, without use of the preparative ultracentrifuge. Clin Chem 18(6): 499-502

16. Early Treatment Diabetic Retinopathy Study Research Group (1991) Grading diabetic retinopathy from stereoscopic color fundus photographs-an extension of the modified Airlie House classification. ETDRS report number 10. Ophthalmology 98:786-806

17. Levey AS, Stevens LA, Schmid CH et al (2009) A new equation to estimate glomerular filtration rate. Ann Intern Med 150(9):604 612. https://doi.org/10.7326/0003-4819-150-9-200905050-00006

18. Ardern CI, Katzmarzyk PT, Janssen I, Church TS, Blair SN (2005) Revised adult treatment panel III guidelines and cardiovascular disease mortality in men attending a preventive medical clinic. Circulation 112(10):1478-1485. https://doi.org/10.1161/ CIRCULATIONAHA.105.548198

19. Ethier C, Lacy P, Davoine F (2014) Identification of human eosinophils in whole blood by flow cytometry. Methods Mol Biol 1178: 81-92. https://doi.org/10.1007/978-1-4939-1016-8 8

20. Fadini GP, Fiala M, Cappellari R et al (2015) Diabetes limits stem cell mobilization following G-CSF but not plerixafor. Diabetes 64(8):2969-2977. https://doi.org/10.2337/db15-0077

21. Albiero M, Ciciliot S, Tedesco S et al (2019) Diabetes-associated myelopoiesis drives stem cell mobilopathy through an OSMp66Shc signaling pathway. Diabetes 68(6):1303-1314. https://doi. org $/ 10.2337 / \mathrm{db} 19-0080$

22. De Palma M, Biziato D, Petrova TV (2017) Microenvironmental regulation of tumour angiogenesis. Nat Rev Cancer 17(8):457-474. https://doi.org/10.1038/nrc.2017.51 
23. Asosingh K, Vasanji A, Tipton A et al (2016) Eotaxin-rich proangiogenic hematopoietic progenitor cells and CCR3+ endothelium in the atopic asthmatic response. J Immunol 196(5):23772387. https://doi.org/10.4049/jimmunol.1500770

24. Puxeddu I, Ribatti D, Crivellato E, Levi-Schaffer F (2005) Mast cells and eosinophils: a novel link between inflammation and angiogenesis in allergic diseases. J Allergy Clin Immunol 116(3):531536. https://doi.org/10.1016/j.jaci.2005.06.007

25. Martin A, Komada MR, Sane DC (2003) Abnormal angiogenesis in diabetes mellitus. Med Res Rev 23(2):117-145. https://doi.org/10. 1002/med.10024

26. Ferrannini E, Muscelli E, Frascerra S et al (2014) Metabolic response to sodium-glucose cotransporter 2 inhibition in type 2 diabetic patients. J Clin Invest 124(2):499-508. https://doi.org/10. 1172/JCI72227

27. Al-Mashhadi RH, Bjorklund MM, Mortensen MB et al (2015) Diabetes with poor glycaemic control does not promote atherosclerosis in genetically modified hypercholesterolaemic minipigs. Diabetologia 58(8):1926-1936. https://doi.org/10.1007/s00125015-3637-1
28. Soedamah-Muthu SS, Fuller JH, Mulnier HE, Raleigh VS, Lawrenson RA, Colhoun HM (2006) High risk of cardiovascular disease in patients with type 1 diabetes in the U.K.: a cohort study using the general practice research database. Diabetes Care 29(4): 798-804. https://doi.org/10.2337/diacare.29.04.06.dc05-1433

29. Nathan DM, Cleary PA, Backlund JY et al (2005) Intensive diabetes treatment and cardiovascular disease in patients with type 1 diabetes. N Engl J Med 353(25):2643-2653. https://doi.org/10.1056/ NEJMoa052187

30. Nagareddy PR, Murphy AJ, Stirzaker RA et al (2013) Hyperglycemia promotes myelopoiesis and impairs the resolution of atherosclerosis. Cell Metab 17(5):695-708. https://doi.org/10. 1016/j.cmet.2013.04.001

31. Wynn TA (2015) Type 2 cytokines: mechanisms and therapeutic strategies. Nat Rev Immunol 15(5):271-282. https://doi.org/10. 1038/nri3831

Publisher's note Springer Nature remains neutral with regard to jurisdictional claims in published maps and institutional affiliations. 